\title{
Autonomic function testing in spinocerebellar ataxia type 2
}

\author{
Elisabetta Indelicato ${ }^{1} \cdot$ Alessandra Fanciulli $^{1} \odot$. Jean Pierre Ndayisaba ${ }^{1} \cdot$ Wolfgang Nachbauer $^{1} \cdot$ Roberta Granata $^{1}$.

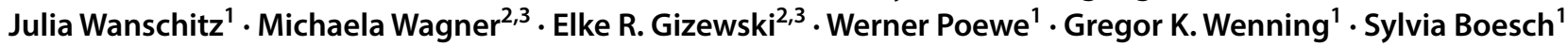

Received: 15 November 2017 / Accepted: 16 January 2018 / Published online: 12 February 2018

(c) The Author(s) 2018

\begin{abstract}
Purpose To assess whether autonomic failure belongs to the clinical spectrum of spinocerebellar ataxia type 2 (SCA2), an autosomal dominant genetic disorder showing progressive cerebellar and brainstem dysfunction.

Methods We evaluated cardiovascular autonomic function in 8 patients with SCA2 and 16 age- and gender-matched healthy controls. Other autonomic domains were examined through standardized questionnaires and by testing the skin sympathetic reflex.

Results Patients with SCA2 showed normal responses to cardiovascular autonomic function tests, with the exception of lower baroreflex sensitivity upon standing compared to controls. In questionnaires, 7 out of 8 patients reported bladder disturbances, while 3 out of 6 tested patients had no skin sympathetic reflex.

Conclusions We did not observe clinically overt cardiovascular autonomic failure in patients with SCA2. Other autonomic domains (i.e., bladder and sudomotor function) may be affected in the disease.
\end{abstract}

Keywords Spinocerebellar ataxia type 2 - Olivo-ponto-cerebellar atrophy $\cdot$ Cardiovascular autonomic function testing . Orthostatic hypotension $\cdot$ Skin sympathetic reflex

\section{Introduction}

Spinocerebellar ataxia type 2 (SCA2) is a rare inherited neurodegenerative disorder characterized by chronic progressive cerebellar and brainstem dysfunction [20]. The disorder is caused by a CAG repeat expansion in the ATXN2 gene and is transmitted in an autosomal dominant manner [20]. SCA2 represents one of the most frequent autosomal dominant

Elisabetta Indelicato and Alessandra Fanciulli share first authorship.

Electronic supplementary material The online version of this article (https://doi.org/10.1007/s10286-018-0504-4) contains supplementary material, which is available to authorized users.

Alessandra Fanciulli

alessandra.fanciulli@i-med.ac.at

1 Department of Neurology, Medical University of Innsbruck, Anichstrasse 35, 6020 Innsbruck, Austria

2 Department of Neuroradiology, Innsbruck Medical University, Innsbruck, Austria

3 Neuroimaging Research Core Facility, Innsbruck Medical University, Innsbruck, Austria ataxias worldwide, and the commonest overall in some geographical spots (e.g., Holguìn province in Cuba) [5]. Disease onset is typically in the 2 nd to 4 th decades of life with a progressive cerebellar syndrome plus additional features, like slowing of saccade velocity, pyramidal signs, parkinsonism and dementia $[16,20]$. Neuropathological studies in SCA2 revealed marked olivo-ponto-cerebellar atrophy, pallor of the substantia nigra and frontal lobe atrophy $[11,20]$. Such atrophy pattern highly resembles that of multiple system atrophy (MSA), a sporadic form of olivo-ponto-cerebellar atrophy. SCA2 may even display pontine hyperintensities at MRI, the so-called hot-cross-bun sign, which is considered typical of MSA [2].

Cardiovascular autonomic failure manifests with baroreflex impairment and orthostatic hypotension [i.e., a sustained decrease of systolic blood pressure (BP) $\geq 20 \mathrm{mmHg}$ or diastolic $\mathrm{BP} \geq 10 \mathrm{mmHg}$ within 3 min of orthostatic challenge] [10] and has been often described in neurodegenerative disorders with brainstem involvement [1].

Detection of cardiovascular autonomic failure in neurological disorders substantially influences both diagnosis and prognosis $[1,6]$. Orthostatic hypotension is indeed a key diagnostic criterion of MSA of cerebellar type (MSA-C). 
The clinical presentation of MSA-C may overlap that of inherited spinocerebellar ataxias, thus representing a relevant differential diagnosis in the absence of a clear family history $[8,12]$.

Few clinical studies have previously examined autonomic function in patients with SCA2 $[4,15,18]$. Symptoms of orthostatic intolerance, gastrointestinal, urogenital and sweating disturbances were reported, but most studies were published prior to current consensus criteria for the diagnosis of orthostatic hypotension [10], did not always provide a comparison with age- and gender-matched healthy controls, nor assessed autonomic symptoms through validated questionnaires [4].

Here, we report the findings of a detailed autonomic investigation performed in a genetically confirmed middle European SCA2 cohort versus age- and gender-matched healthy controls.

\section{Methods}

\section{Study population}

Eight patients with genetically confirmed SCA2 and 16 age- and gender-matched healthy controls were enrolled in the present study. The study protocol was approved by the local ethical committee and written informed consent was collected from both patients and controls. All investigations were conducted in accordance with the Declaration of Helsinki.

\section{Clinical evaluation}

Basic clinical-demographic data, as well as results of genetic testing, were collected for all patients. All patients underwent a general and a neurological examination. Disease severity was evaluated with the scale for the assessment and rating of ataxia (SARA) [21]. Laboratory testing was performed to rule out disorders of glucose metabolism, vitamin deficiency or thyroid dysfunction. In the routine work-up, all patients had undergone nerve conduction studies and cerebral MRI. ECG was performed in all patients, while echocardiography was performed in 6 of them.

\section{Cardiovascular autonomic function assessment}

On the day of cardiovascular autonomic function testing, patients and healthy controls were invited not to drink any coffee, tea or taurine-containing beverages and to have their meals at least $2 \mathrm{~h}$ before the scheduled examination. All tests were performed between 09:00 a.m. and 12:00 p.m. The test battery included: $10 \mathrm{~min}$ supine, $10 \mathrm{~min} 60^{\circ}$ headup tilt, 5 min supine, 5 min active standing, metronomic deep breathing at 6 cycles/min for $1 \mathrm{~min}$ and the Valsalva manoeuvre under continuous non-invasive heart rate and BP monitoring (Task Force ${ }^{\circledR}$ Monitor, CNSystems 2007). Deep-breathing and Valsalva ratio were calculated following standardized methodology [17]. BP contra regulatory behaviour during the late phase II (II_L) and phase IV of the Valsalva manoeuvre were also evaluated as further indices of vascular noradrenergic control [7]. Baroreflex sensitivity in the supine position and during active standing was calculated according to the sequence method [17]. Every patient performed at least the head-up tilt or the active standing.

\section{Further autonomic evaluations}

Autonomic symptoms were investigated by means of two questionnaires, the SCOPA-AUT and the Orthostatic Hypotension Questionnaire (OHQ) [13, 24]. Sudomotor function was evaluated by testing the skin-sympathetic reflex in 6 patients. Sympathetic skin responses after tibial nerve stimulation were recorded from both feet with surface electrodes. The skin sympathetic reflex was rated as "absent", if skin responses were missing in both feet.

\section{Statistical analysis}

Statistical analysis was performed with SPSS 24.0. Categorical variables are reported as percentages, while continuous variables are reported as mean and standard deviation or median and interquartile range depending on their distribution, verified by means of the Shapiro-Wilk test. Comparisons between patients and healthy controls were performed by means of unpaired $t$ test or ANOVA for repeated measurements (where necessary) for normally distributed variables. The Mann-Whitney $U$ test was applied for not normally distributed values. Statistical significance was set at $p<0.05$.

\section{Results}

\section{Clinical-demographic data}

Our SCA 2 cohort consisted of 8 patients ( 3 women, 5 men) from 5 pedigrees (see Table 1). Median age at examination was 49 years (range 29-56) and mean disease duration was $13 \pm 5$ years. The average SARA score was $18.3 \pm 5.2$, which corresponds to moderate ataxia with gait dependent upon devices [23]. Two patients suffered from arterial hypertension; echocardiography was unremarkable in one and showed a mild concentric left ventricular hypertrophy in the other. Two patients were under chronic levothyroxine treatment and had stable thyroid function parameter at the time of evaluation. Four patients had pathological nerve 
Table 1 Clinical and demographic data for each patient and the whole cohort are shown

\begin{tabular}{|c|c|c|c|c|c|c|c|c|c|}
\hline & $\mathrm{I}-1$ & II-1 & III-1 & III-2 & IV-1 & IV-2 & IV-3 & $\mathrm{V}-1$ & Total cohor \\
\hline Age & 48 & 31 & 55 & 50 & 54 & 31 & 29 & 56 & $49(29 ; 56)$ \\
\hline Disease duration & 12 & 6 & 20 & 12 & 15 & 12 & 19 & 7 & $13 \pm 5$ \\
\hline $\begin{array}{l}\text { CAG repeats (expanded } \\
\text { allele) }\end{array}$ & 40 & 40 & 40 & 40 & 41 & 46 & 44 & 45 & $42 \pm 6$ \\
\hline SARA score & 25 & 8,5 & 19 & 17,5 & 18 & 25,5 & 18,5 & 14 & $18,3 \pm 5,2$ \\
\hline $\begin{array}{l}\text { Cardiovascular comor- } \\
\text { bidities }\end{array}$ & No & No & No & Yes & Yes & No & No & No & $2 / 8(25 \%)$ \\
\hline SCOPA-aut total score & $\mathrm{NA}^{\mathrm{a}}$ & 3 & 3 & 31 & 14 & 3 & 7 & 3 & $3(3 ; 31)$ \\
\hline Swallowing & - & 0 & 0 & 2 & 0 & 1 & 0 & 0 & $0(0 ; 1)$ \\
\hline Cardiovascular & - & 0 & 0 & 3 & 0 & 0 & 0 & 0 & $0(0 ; 0)$ \\
\hline Bladder & - & 1 & 3 & 7 & 8 & 0 & 2 & 1 & $2(1 ; 7)$ \\
\hline Sexual & - & 2 & 0 & 0 & 4 & 0 & 0 & 0 & $0(0 ; 2)$ \\
\hline Gastrointestinal & - & 0 & 0 & 6 & 2 & 2 & 0 & 1 & $1(0 ; 2)$ \\
\hline Sweating & - & 0 & 0 & 6 & 0 & 0 & 2 & 1 & $0(0 ; 0)$ \\
\hline Thermoregulation & - & 0 & 0 & 4 & 0 & 0 & 2 & 0 & $0(0 ; 0)$ \\
\hline Pupillomotor & - & 0 & 0 & 3 & 0 & 0 & 1 & 0 & $0(0 ; 0)$ \\
\hline OHQ & 0 & 0 & 0 & 0 & 0 & 0 & 0 & 0 & 0 \\
\hline Atrophy pattern at MRI & OPCA & OPCA & OPCA & OPCA & OPCA & OPCA & OPCA & OPCA & $8 / 8(100 \%)$ \\
\hline Nerve conduction study & $\begin{array}{l}\text { Axonal sensory- } \\
\text { motor neuropa- } \\
\text { thy }\end{array}$ & $\begin{array}{l}\text { Sensory } \\
\text { neurop- } \\
\text { athy }\end{array}$ & Normal & $\begin{array}{l}\text { Axonal sensory- } \\
\text { motor neuropa- } \\
\text { thy }\end{array}$ & Normal & Normal & Normal & $\begin{array}{l}\text { Axonal sensory- } \\
\text { motor neuropa- } \\
\text { thy }\end{array}$ & - \\
\hline SSR right foot & NA & & & & Absent & Absent & Absent & NA & - \\
\hline Latency (ms) & & 2187 & 1200 & 1876 & & & & & \\
\hline Amplitude (mV) & & 0.50 & 0.41 & 0.20 & & & & & \\
\hline SSR left foot & NA & & & & Absent & Absent & Absent & NA & - \\
\hline Latency (ms) & & 2243 & 2043 & 2164 & & & & & \\
\hline Amplitude (mV) & & 0.81 & 0.40 & 0.19 & & & & & \\
\hline
\end{tabular}

Pedigrees are indicated by roman numbers (from I to V). Values are reported as median (range), mean \pm standard deviation or as percentage, according to their distribution

$O P C A$ olivo-ponto-cerebellar atrophy, SSR skin sympathetic reflex, $N A$ not available

${ }^{\text {a }}$ Review of medical records for autonomic symptoms revealed urinary urge and frequency with evidence of overactive bladder detrusor at urodynamic examination in this patient

conduction studies, with axonal sensory-motor neuropathy in three of them and pure sensory neuropathy in the other. At MRI, all patients displayed brainstem and cerebellar atrophy and two showed a hot-cross-bun sign (see supplementary Fig. 1).

\section{Autonomic findings}

The median SCOPA-AUT score was 3 (range 3-31). Two outliers, with scores of 14 and 31, were represented by two patients suffering, respectively, from comorbidities unrelated to the underlying neurological disorder (gastric resection and benign prostatic hypertrophy in one case and irritable bowel syndrome in the other). The most frequent complaints were bladder disturbances (7 out of 8 patients), such as increased voiding frequency and/or nocturia (see Table 1). All patients scored zero at the OHQ.
Results from cardiovascular function testing are reported in Table 2. Neither patients nor healthy controls reported symptoms of orthostatic intolerance during cardiovascular autonomic function testing. No patient with SCA2 fulfilled the criteria for orthostatic hypotension, postural orthostatic tachycardia syndrome or experienced syncope during tilttest examination [10]. In comparison with healthy controls, ANOVA for repeated measurements did not disclose any differences concerning both resting parameters, as well as cardiovascular responses to head-up tilt and active standing. SCA2 patients showed higher, though not significant, supine heart rate (HR) values, with preserved HR increase during orthostatic challenge.

SCA2 patients tended to have lower Valsalva and deep breathing ratios compared to the healthy controls, albeit such differences were not statistically significant. SCA2 patients showed a regular BP overshoot in the phase II-L and IV of 
Table 2 Cardiovascular autonomic function tests in patients with SCA2 and ageand gender-matched healthy controls

\begin{tabular}{|c|c|c|c|}
\hline Test & $\begin{array}{l}\text { SCA2 } \\
n=8, \text { age } 49(31 ; 55)\end{array}$ & $\begin{array}{l}\text { Controls } \\
n=16, \text { age } 49(30 ; 55)\end{array}$ & $p$ \\
\hline Head-up tilt & $n=5$, age $48(31 ; 52)$ & $n=10$, age $47(31 ; 53)$ & \\
\hline \multicolumn{4}{|l|}{ Supine rest } \\
\hline Heart rate & $71.6 \pm 14.5$ & $61.4 \pm 8.6$ & NS \\
\hline Systolic BP & $108(106.5 ; 124.5)$ & $112.5(105.3 ; 121)$ & NS \\
\hline Diastolic BP & $75.8 \pm 15.5$ & $73.8 \pm 7.1$ & NS \\
\hline \multicolumn{4}{|l|}{$3^{\prime}$ minute tilt } \\
\hline$\Delta$ heart rate & $+13 \pm 7.8$ & $+11.9 \pm 8$ & NS \\
\hline$\Delta$ systolic BP & $+4.8 \pm 6.1$ & $+9.2 \pm 5.9$ & NS \\
\hline$\Delta$ diastolic BP & $+14(7.5 ; 15.5)$ & $+11(10 ; 13.8)$ & NS \\
\hline \multicolumn{4}{|l|}{$10^{\prime}$ minute tilt } \\
\hline$\Delta$ heart rate & $+16.6 \pm 7$ & $+12.8 \pm 8$ & NS \\
\hline$\Delta$ systolic BP & $+3(-0.5 ; 6.5)$ & $+14(3 ; 16.3)$ & NS \\
\hline$\Delta$ diastolic $\mathrm{BP}$ & $+3.8 \pm 6.2$ & $+10.6 \pm 7.8$ & NS \\
\hline Active standing & $n=7$, age $50(31 ; 55)$ & $n=14$, age $50(31 ; 55)$ & \\
\hline \multicolumn{4}{|l|}{ Supine rest } \\
\hline Heart rate & $71.4 \pm 14.6$ & $62.6 \pm 7$ & NS \\
\hline Systolic BP & $111.9 \pm 16.7$ & $116.4 \pm 14.7$ & NS \\
\hline Diastolic BP & $74.4 \pm 12.5$ & $70.1 \pm 12.5$ & NS \\
\hline \multicolumn{4}{|l|}{ 3' minute standing } \\
\hline$\Delta$ heart rate & $+17.3 \pm 7.5$ & $+19.5 \pm 6.7$ & NS \\
\hline$\Delta$ systolic BP & $+18.7 \pm 7.5$ & $+14.9 \pm 15$ & NS \\
\hline$\Delta$ diastolic BP & $+17.9 \pm 9.5$ & $+22.3 \pm 14.4$ & NS \\
\hline \multicolumn{4}{|l|}{$5^{\prime}$ minute standing } \\
\hline$\Delta$ heart rate & $+17 \pm 7.7$ & $+19.8 \pm 6.6$ & NS \\
\hline$\Delta$ systolic BP & $+8(4.8 ; 26)$ & +18.5(10.8; 25.5) & NS \\
\hline$\Delta$ diastolic $\mathrm{BP}$ & $+14.3 \pm 8$ & $+22.3 \pm 14$ & NS \\
\hline Baroreflex sensitivity & $n=5$, age $48(31 ; 52)$ & $n=10$, age $47(31 ; 53)$ & \\
\hline Supine & $11.7(5.8 ; 14.9)$ & $16.7(11.9 ; 24.5)$ & NS \\
\hline Standing & $3.7 \pm 1.7$ & $9.1 \pm 0.6$ & 0.002 \\
\hline Deep breathing & $n=7$, age $50(31 ; 55)$ & $n=14$, age $50(31 ; 55)$ & \\
\hline Deep breathing ratio & $14.1 \pm 10.6$ & $20.6 \pm 6.3$ & NS \\
\hline Valsalva manoeuvre & $n=6$, age $52(31 ; 55)$ & $n=12$, age $53(31 ; 56)$ & \\
\hline Valsalva ratio & $1.4(1.37-2.06)$ & $1.8(1.62 ; 1.98)$ & NS \\
\hline$\Delta$ II_L-II_e mean BP & $+12.1 \pm 10.3$ & $+9.1 \pm 5.6$ & NS \\
\hline$\Delta$ IV-I mean BP & $+7.8 \pm 7$ & $+6.5 \pm 7.7$ & NS \\
\hline
\end{tabular}

Values are represented as mean \pm standard deviation or as median (1st quartile; 3rd quartile) according to their distribution

$N S$ not significant, $B P$ blood pressure the Valsalva manoeuvre. Baroreflex sensitivity in the supine position did not differ between SCA2 patients and controls, whereas SCA2 patients showed a significantly lower baroreflex sensitivity under orthostatic challenge $(p=0.002)$.
Skin sympathetic reflex was absent in 3 out of 6 patients. These patients were members of the same pedigree and had unremarkable nerve conduction studies (see Table 1). 


\section{Discussion}

Symptoms of overactive bladder were the most frequent autonomic disturbance reported by patients with SCA 2 in the present study. This finding is in agreement with previous studies, reporting bladder and gastrointestinal symptoms as the most common autonomic features among SCA 2 patients [14, 15, 22].

In our cohort, no patient complained of orthostatic symptoms, which had been reported by $5-13 \%$ of SCA 2 patients at SCOPA-AUT questionnaire in previous studies $[14,15,22]$. Here, we used the OHQ, which, being a dedicated questionnaire, may better differentiate true orthostatic symptoms from dizziness or visual disturbances upon position changes due to the underlying cerebellar syndrome.

We observed a largely preserved cardiovascular autonomic function in patients with SCA2. None of the patients showed orthostatic hypotension [10]. Other studies investigating cardiovascular autonomic function in SCA2 patients of Latin American ancestry also did not observe any difference in orthostatic BP behaviour between SCA2 patients and controls $[14,15]$.

SCA2 patients had a blunted baroreflex sensitivity upon orthostatic challenge with respect to controls. Impaired baroreflex sensitivity was previously reported by MontesBrown et al. in symptomatic and presymptomatic SCA2 mutation carriers, and possibly reflects the neuropathological involvement of brainstem autonomic nuclei in the disease $[14,15]$. However, given the long disease duration and already advanced disease stage of our patients, it appears unlikely for such a finding to evolve into clinically manifest orthostatic hypotension later in the disease course.

Other studies reported cardiovascular autonomic abnormalities in SCA2 patients, but the magnitude of BP fall and/ or tachycardia response were not specified [4], or different criteria were applied to diagnose orthostatic hypotension [18]. Another case report on early onset SCA2 pointed out a marked autonomic dysfunction as part of the phenotypic spectrum, but related symptoms were not described [19]. To date, overt orthostatic hypotension has been documented in one patient with SCA2 only [3].

On the basis of the present findings, we conclude that, in spite of the marked brainstem atrophy present in all our patients, overt cardiovascular autonomic failure is not a major feature of SCA2. Nonetheless, involvement of other autonomic domains (i.e., bladder, sudomotor function) may occur $[9,11]$.

The main shortcoming of this study is represented by the small sample size, which mostly reflects the rarity of the disease in the middle European population. Larger confirmatory studies are required in order to shed light on the possible determinants of selective autonomic disturbances in SCA2.

Acknowledgements Open Access Funding provided by University of Innsbruck and Medical University of Innsbruck.

\section{Compliance with ethical standards}

Conflict of interests The authors declare that they have no conflict of interest.

Open Access This article is distributed under the terms of the Creative Commons Attribution 4.0 International License (http://creativeco mmons.org/licenses/by/4.0/), which permits unrestricted use, distribution, and reproduction in any medium, provided you give appropriate credit to the original author(s) and the source, provide a link to the Creative Commons license, and indicate if changes were made.

\section{References}

1. Benarroch EE (2014) The clinical approach to autonomic failure in neurological disorders. Nat Rev Neurol 10:396-407

2. Burk K, Skalej M, Dichgans J (2001) Pontine MRI hyperintensities ("the cross sign") are not pathognomonic for multiple system atrophy (MSA). Mov Disord 16:535

3. Capozzo R, Rizzo G, De Mari M, Tortorella C, Logroscino G (2015) Early and severe autonomic failure: broadening the clinical phenotype of type-2 spinocerebellar ataxia. A case report. $\mathrm{J}$ Neurol 262:224-225

4. De Joanna G, De Rosa A, Salvatore E, Castaldo I, De Luca N, Izzo R, Manzo V, Filla A, De Michele G (2008) Autonomic nervous system abnormalities in spinocerebellar ataxia type 2: a cardiovascular neurophysiologic study. J Neurol Sci 275:60-63

5. Durr A (2010) Autosomal dominant cerebellar ataxias: polyglutamine expansions and beyond. Lancet Neurol 9:885-894

6. Fanciulli A, Strano S, Colosimo C, Caltagirone C, Spalletta G, Pontieri FE (2013) The potential prognostic role of cardiovascular autonomic failure in alpha-synucleinopathies. Eur J Neurol 20:231-235

7. Fanciulli A, Strano S, Ndayisaba JP, Goebel G, Gioffre L, Rizzo M, Colosimo C, Caltagirone C, Poewe W, Wenning GK, Pontieri FE (2014) Detecting nocturnal hypertension in Parkinson's disease and multiple system atrophy: proposal of a decision-support algorithm. J Neurol 261:1291

8. Fanciulli A, Wenning GK (2015) Multiple-system atrophy. N Engl J Med 372:1375-1376

9. Filla A, De Michele G, Santoro L, Calabrese O, Castaldo I, Giuffrida S, Restivo D, Serlenga L, Condorelli DF, Bonuccelli U, Scala R, Coppola G, Caruso G, Cocozza S (1999) Spinocerebellar ataxia type 2 in southern Italy: a clinical and molecular study of 30 families. J Neurol 246:467-471

10. Freeman R, Wieling W, Axelrod FB, Benditt DG, Benarroch E, Biaggioni I, Cheshire WP, Chelimsky T, Cortelli P, Gibbons CH, Goldstein DS, Hainsworth R, Hilz MJ, Jacob G, Kaufmann H, Jordan J, Lipsitz LA, Levine BD, Low PA, Mathias C, Raj SR, Robertson D, Sandroni P, Schatz I, Schondorff R, Stewart JM, van Dijk JG (2011) Consensus statement on the definition of orthostatic hypotension, neurally mediated syncope and the postural tachycardia syndrome. Clin Auton Res 21:69-72

11. Gierga K, Burk K, Bauer M, Orozco Diaz G, Auburger G, Schultz C, Vuksic M, Schols L, de Vos RA, Braak H, Deller T, 
Rub U (2005) Involvement of the cranial nerves and their nuclei in spinocerebellar ataxia type 2 (SCA2). Acta Neuropathol 109:617-631

12. Giordano I, Harmuth F, Jacobi H, Paap B, Vielhaber S, Machts J, Schols L, Synofzik M, Sturm M, Tallaksen C, Wedding IM, Boesch S, Eigentler A, van de Warrenburg B, van Gaalen J, Kamm C, Dudesek A, Kang JS, Timmann D, Silvestri G, Masciullo M, Klopstock T, Neuhofer C, Ganos C, Filla A, Bauer P, Tezenas du Montcel S, Klockgether T (2017) Clinical and genetic characteristics of sporadic adult-onset degenerative ataxia. Neurology 89:1043-1049

13. Kaufmann H, Malamut R, Norcliffe-Kaufmann L, Rosa K, Freeman R (2012) The orthostatic hypotension questionnaire (OHQ): validation of a novel symptom assessment scale. Clin Auton Res 22:79-90

14. Montes-Brown J, Machado A, Estevez M, Carricarte C, Velazquez-Perez L (2012) Autonomic dysfunction in presymptomatic spinocerebellar ataxia type-2. Acta Neurol Scand 125:24-29

15. Montes-Brown J, Sanchez-Cruz G, Garcia AM, Baez ME, Velazquez-Perez L (2010) Heart rate variability in type 2 spinocerebellar ataxia. Acta Neurol Scand 122:329-335

16. Moscovich M, Okun MS, Favilla C, Figueroa KP, Pulst SM, Perlman S, Wilmot G, Gomez C, Schmahmann J, Paulson H, Shakkottai V, Ying S, Zesiewicz T, Kuo SH, Mazzoni P, Bushara K, Xia G, Ashizawa T, Subramony SH (2015) Clinical evaluation of eye movements in spinocerebellar ataxias: a prospective multicenter study. J Neuro-Ophthalmol 35:16-21

17. Ndayisaba JP, Fanciulli A, Granata R, Duerr S, Hintringer F, Goebel G, Krismer F, Wenning GK (2015) Sex and age effects on cardiovascular autonomic function in healthy adults. Clin Auton Res 25:317-326

18. Netravathi M, Sathyaprabha TN, Jayalaxmi K, Datta P, Nirmala M, Pal PK (2009) A comparative study of cardiac dysautonomia in autosomal dominant spinocerebellar ataxias and idiopathic sporadic ataxias. Acta Neurol Scand 120:204-209

19. Paciorkowski AR, Shafrir Y, Hrivnak J, Patterson MC, Tennison MB, Clark HB, Gomez CM (2011) Massive expansion of SCA2 with autonomic dysfunction, retinitis pigmentosa, and infantile spasms. Neurology 77:1055-1060

20. Rub U, Schols L, Paulson H, Auburger G, Kermer P, Jen JC, Seidel K, Korf HW, Deller T (2013) Clinical features, neurogenetics and neuropathology of the polyglutamine spinocerebellar ataxias type 1, 2, 3, 6 and 7. Prog Neurobiol 104:38-66

21. Schmitz-Hubsch T, du Montcel ST, Baliko L, Berciano J, Boesch S, Depondt C, Giunti P, Globas C, Infante J, Kang JS, Kremer B, Mariotti C, Melegh B, Pandolfo M, Rakowicz M, Ribai P, Rola R, Schols L, Szymanski S, van de Warrenburg BP, Durr A, Klockgether T, Fancellu R (2006) Scale for the assessment and rating of ataxia: development of a new clinical scale. Neurology 66:1717-1720

22. Velazquez-Perez L, Rodriguez-Labrada R, Cruz-Rivas EM, Fernandez-Ruiz J, Vaca-Palomares I, Lilia-Campins J, Cisneros B, Pena-Acosta A, Vazquez-Mojena Y, Diaz R, Magana-Aguirre JJ, Cruz-Marino T, Estupinan-Rodriguez A, Laffita-Mesa JM, Gonzalez-Pina R, Canales-Ochoa N, Gonzalez-Zaldivar Y (2014) Comprehensive study of early features in spinocerebellar ataxia 2: delineating the prodromal stage of the disease. Cerebellum 13:568-579

23. Velazquez-Perez LC, Rodriguez-Labrada R, Fernandez-Ruiz J (2017) Spinocerebellar ataxia type 2: clinicogenetic aspects, mechanistic insights, and management approaches. Front Neurol $8: 472$

24. Visser M, Marinus J, Stiggelbout AM, Van Hilten JJ (2004) Assessment of autonomic dysfunction in Parkinson's disease: the SCOPA-AUT. Mov Disord 19:1306-1312 